\title{
Modelling comparison to evaluate the importance of phenology and spring frost damage for the effects of climate change on growth of mixed temperate-zone deciduous forests
}

\author{
Koen Kramer ${ }^{1, *}$, Andrew Friend ${ }^{2}$, Ilkka Leinonen ${ }^{3}$ \\ 'Institute for Forestry and Nature Research, IBN-DL.O, PO Box 23,6700 AA Wageningen, The Netherlands \\ ${ }^{2}$ Institute of Terrestrial Ecology, Edinburgh Research Station, Bush Estate, Peninuick, Midlothian EH26 0QB, United Kingdom \\ ${ }^{3}$ University of Joensuu, Faculty of Forestry, PO Box 111, FIN-80101 Joensuu, Finland
}

\begin{abstract}
The importance of 3 phenological types of deciduous tree, and the effects of the occurrence of frost damage on growth of mixed-species forests, were evaluated using the models FORGRO and HYBRID. The climate change scenarios used were a doubling of the $\mathrm{CO}_{2}$ concentration $(700 \mu \mathrm{mol}$ $\mathrm{mol}^{-1}$ ) and an increase in temperature ranging from 0 to $7^{\circ} \mathrm{C}$. Both FORGRO and HYBRID are mechanistic models treating eco-physiological processes in detail. FORGRO highlights potential growth in managed forests where all individuals of one species are of the same age and size, whereas HYBRID highlights growth in natural forests, including regeneration, and mortality of individual trees that differ in age and size. Furthermore, the importance of inaccurate prediction of phenological events and frost hardiness for growth in mixed-species stands was evaluated by comparing dynamic models to regression models. The dynamic models predict the timing of phenological events annually and the progression of frost hardiness during dormancy, whereas the regression models represent empirical relationships between the change in the average date of phenological events with a rise in mean winter temperature and the level of frost hardiness at the moment of leaf unfolding. The results of the climate change scenarios indicate for both FORGRO and HYBRID that: (1) the differences in net primary production (NPP) of the 3 phenological types considered are enhanced when grown in a mixed-species stand compared to a monospecies stand; and (2) the effects of frost damage on growth are more prominent in mixed-species stands than in monospecies stands. Regarding the accuracy of the dynamic approach compared to the regression approach for predicting the timing of leaf unfolding and spring frost damage, the dynamic approach for leaf unfolding results in a similar response of NPP to the regression approach, both for the monospecies and the mixed-species situation. The dynamic approach, however, yields larger differences in the NPP between the phenological types because the model predicts a greater advancement of leaf unfolding than does the regression approach. Comparing the regression approach to the dynamic approach with regard to frost hardiness, the regression approach shows a greater frequency of frost damage; because, according to the dynamic approach the minimum level of frost hardiness is attained after the date of leaf unfolding, thus reducing this frequency.
\end{abstract}

KEY WORDS: Climate change · Deciduous trees · Growth · Models · Mixed-species forests · Phenology

\section{INTRODUCTION}

Phenology is the study of the timing of annually recurring events such as leaf unfolding and leaf fall, as related to climatic and other environmental factors

·E-mail: k.kramer@ibn.dlo.nl
(Lieth 1974). It can be assumed that this timing is such that the growing period is optimally synchronised with the period favourable for growth, by either natural selection or management. If a significant climate change occurs within the life span of a tree, then this synchronization may be disrupted. In earlier studies, the effects of temperature increase on phenology and 
on the occurrence of spring frost damage and its consequences for growth of monospecies stands were evaluated (Kramer 1994, 1995b). Species were found to respond differently to the imposed climate change scenarios. Consequently, the competitive relationships between these species, when grown in mixed stands, will alter due to climate change. The term competition is used to mean the reduction in growth of a target species, caused by the presence of another species requiring the same limiting resource. In this study, only differences affecting competition for light were considered.

With respect to phenology and spring frost damage, species differed: (1) in the extent to which the date of leaf unfolding advanced with increasing winter temperature, and thus (2) in the frequency of freezing temperatures to which they were subjected around this date. Species that unfold their leaves during the end of April appear to respond more strongly to temperature change than species that unfold their leaves during the first weeks of May (Kramer 1994). Such a differential response enhances existing differences between species if temperature increases. This may have consequences for the occurrence of frost damage and for the competition for light. Thus, by evaluating the relationship between temperature and both leaf unfolding and leaf fall, and the progression of frost hardiness, both the direct effects of climatic warming (on frost damage) and indirect effects (on competitive ability) are accounted for. The available phenological models are, however, not very accurate (Kramer 1995a). Therefore, in this study both a regression approach and a dynamic approach were taken, enabling evaluation of the inaccuracy of the models for growth in a mixed-species stand.

A previous study (Kramer 1995b) showed that, with respect to growth of a monospecies stand, the difference between phenological types in the response of gross photosynthesis to temperature scenarios given a doubled $\mathrm{CO}_{2}$ concentration ranged from 4 to $20 \%$ if the corresponding temperature rose by 2 to $7^{\circ} \mathrm{C}$, respectively. These differences may be enhanced when species are mixed, especially in combination with an altered occurrence of spring frost damage. Therefore, the aims of this study were: (1) to evaluate the effects of differences between species, in both phenological response and occurrence of spring frost damage, on growth in mixed-species deciduous forest stands, in relation to increased temperature and atmospheric $\mathrm{CO}_{2}$ concentration, and (2) to assess the importance of inaccuracy in the prediction of phenological events and frost hardiness for this evaluation.

This was done by comparison of the annual net primary productivity predicted by the models FORGRO and HYBRID, based on a range of climate change sce- narios. Both FORGRO and HYBRID are mechanistic models describing eco-physiological processes (light interception, photosynthesis, respiration and allocation) in detail. FORGRO (Mohren 1987, 1994) aims to predict forest productivity of managed stands based on information about the species, site and management regime considered. HYBRID (Friend 1993, Friend et al. in press) aims to predict vegetation types based on climate and eco-physiological features of general plant types based on climate. For this study the plant type 'cold deciduous tree' was refined to represent several phenological types. The species dynamics are described by establishment of seedlings and subsequent growth of individual trees in a gap, which occurs when a large tree dies. Thus, the key difference between FORGRO and HYBRID is that FORGRO treats a forest stand in which all individuals of a species are of the same age and size, whereas HYBRID treats individual trees differing in age and size. The rationale of such a model comparison is that, if models emphasizing different aspects of forest growth yield similar results, then more confidence is gained in these results. If not, then the differences may be explained by further analysis of the processes in which the models differ.

\section{MATERIAL AND METHODS}

2.1. Phenology and frost hardiness. Two approaches were used to describe the dependency of the date of leaf unfolding and the level of frost hardiness on temperature: (1) a regression approach, represented by empirical relationships between the change in the average date of leaf unfolding with a rise in mean winter temperature, and a constant level of frost hardiness from the moment of leaf unfolding until leaf falli (2) a dynamic approach, using dynamic models that predict both the date of leaf unfolding annually and the progression of frost hardiness during dormancy. Frost damage occurs in both approaches when the daily minimum temperature is less than the level of frost hardiness.

2.1.1. Regression approach: Three types of phenological responses to temperature increase were discerned based on the analysis of an extensive data set containing phenological observations on clones relocated over a large latitudinal range throughout Europe: (1) a similar advance of both leaf unfolding and leaf fall; (2) an advance of leaf unfolding, but no change in leaf fall; and (3) a larger advance of leaf fall than of leaf unfolding (Kramer 1995a). These 3 phenological types correspond to Betula, Fagus, and Quercus, respectively. Table 1 presents the characteristics of these phenological types. The mean dates of both leaf unfolding and leaf fall are kept constant during 
Table 1 Phenological characteristics of Betula, Fagus, and Quercus. $U$ : average date of leaf unfolding, according to both the regression and the dynamic approach for leaf unfolding (Kramer 1994, Tables 1, 4 \& 6); F: date of leaf fall; $P_{0}$ : probability of sub-zero temperature in a symmetric $11 \mathrm{~d}$ period around the date of leaf unfolding; $\delta U / \delta T_{w}$ : change in date of leaf unfolding with mean winter temperature (days per ${ }^{\circ} \mathrm{C}$ ); $T_{\mathrm{w}}$ : period from 1 November until leaf unfolding; $\delta F / \delta T_{\mathrm{s}}$ : change in date of leaf fall with mean summer temperature (days per ${ }^{\circ} \mathrm{C}$ ); $T_{s}$ : period from 1 May until leaf fall; $R^{2}$ : percentage of the variance in the date of leaf unfolding explained by the dynamic approach

\begin{tabular}{|c|c|c|c|}
\hline & Betula & Fagus & Quercus \\
\hline \multicolumn{4}{|c|}{ Regression approach } \\
\hline$U$ & 22 April & 1 May & 6 May \\
\hline$F$ & 4 October & 16 October & 20 October \\
\hline$P_{0}$ & 0.58 & 0.37 & 0.18 \\
\hline$\delta U / \delta T_{w}$ & -3 & -2 & -2 \\
\hline$\delta F / \delta T_{\mathrm{s}}$ & -3 & 0 & -5 \\
\hline \multicolumn{4}{|c|}{ Dynamic approach } \\
\hline$U$ & 22 April & 1 May & 6 May \\
\hline$P_{0}$ & 0.53 & 0.30 & 0.12 \\
\hline$\delta U / \delta T_{w}$ & -5 & -4 & -5 \\
\hline $\mathrm{R}^{2}$ & 86 & 68 & 82 \\
\hline
\end{tabular}

each simulation period representing 1 scenario. If the temperature was increased according to a scenario, then the mean dates of both leaf unfolding and leaf fall were adjusted according to the responses of Betula. Fagus, and Quercus (Table 1). A fixed temperature threshold was taken as the level of frost hardiness, assuming that frost hardiness is at its lowest level from the date of leaf unfolding onwards, and was set at a value of $-2.3^{\circ} \mathrm{C}$ (Friend et al. in press)

2.1.2. Dynamic approach: Sarvas (1974) discerned 2 phases during dormancy of woody plants: (1) Rest, in which growth-arresting conditions in the bud itself prevent the bud from bursting, even when exposed to conditions that are normally favourable for development and growth. The growth-arresting factors can be removed by exposing the buds to chilling temperatures for a prolonged period. (2) Quiescence, in which only unfavourable external conditions prevent the buds from bursting. When brought into favourable temperature conditions, the buds are readily forced to burst. Hänninen (1990) formalised this approach by defining a state of chilling, $S_{c}$, indicating how far rest has progressed, and the state of forcing, $S_{\mathrm{f}}$, indicating how far quiescence has progressed. Sarvas (1974) postulated that these phases occur sequentially in time; thus the state of forcing increases only when the chilling requirements are met, i.e. when the state of chilling attains a critical value, $S_{c^{*}}$. Budburst is predicted to occur when $S_{f}$ attains its critical value, $S_{f}{ }^{*}$. For the rate of chilling, $R_{\mathrm{c}}$, a triangular function with temperature is assumed, and for the rate of forcing, $R_{\mathrm{f}}$, a logistic func- tion with temperature. The values of the parameters of these functions estimated by Kramer (1995a) were used. Table 1 presents the phenological features of the sequential model. For the timing of leaf fall, no model could be found that explained the variance of this date better than the mean (Kramer 1995a). Therefore, only the regression approach was used for the date of leaf fall.

Frost hardiness is the freezing temperature a plant can sustain without being damaged. To describe the progression of frost hardiness, the model developed by Leinonen et al. (1995) for Pinus sylvestris in Finland was used. Empirical results indicate that plants kept in a constant environment attain a stationary level of frost hardiness. If the environment changes, then the actual level of frost hardiness gradually adjusts to the new situation, at a rate that is proportional to the difference between the stationary and the actual level of frost hardiness. However, the competence to adjust to a changed environment is not constant throughout the year but depends on the plant's state of development. The main environmental factors driving the change in the stationary level of frost hardiness are temperature and photoperiod, which appear to operate additively.

Leinonen et al. (1995) formalised these empirical findings by defining a stationary level of frost hardiness, $\hat{S}_{\mathrm{h}}$ (in ${ }^{\circ} \mathrm{C}$ ), which may change either due to a change in temperature, $\Delta \hat{S}_{\mathrm{h}}(\mathrm{T})$, or due to a change in photoperiod, $\Delta \hat{S}_{\mathrm{h}}(\mathrm{P})$, or both, starting from a minimum level of frost hardiness, $\hat{S}_{\mathrm{h}, \mathrm{mun}}$, when the plant is completely dehardened:

$$
\hat{S}_{\mathrm{h}}(t)=\hat{S}_{\mathrm{h}, \min }+\Delta \hat{S}_{\mathrm{h}}(\mathrm{T})+\Delta \hat{S}_{\mathrm{h}}(\mathrm{P})
$$

where $t=$ time. The rate of change of the actual level of frost hardiness, $R_{\mathrm{h}}$, can be described as:

$$
R_{\mathrm{h}}=C_{\mathrm{h}}\left(S_{\mathrm{f}}\right) \cdot 1 / \tau \cdot\left(\hat{S}_{\mathrm{h}}-S_{\mathrm{h}}\right)
$$

where $C_{h}\left(S_{f}\right)$ is the plant's hardening competence as a function of the state of forcing which is determined by the sequential model; $\tau$ is a time coefficient determining how fast the actual level of frost hardiness adjusts to the stationary level when the environment changes; and $S_{\mathrm{h}}$ is the actual state of frost hardiness. The explicit functions and parameter values for $\Delta \hat{S}_{\mathrm{h}}(\mathrm{T}), \Delta \hat{S}_{\mathrm{h}}(\mathrm{P})$, and $C_{h}$ presented by Leinonen et al. (1995) were used.

2.2. Forest growth models. FORGRO (Mohren 1987 1994 , Kramer 1995b) is a process-based primary production model aiming to predict growth of managed stands, using species, site and climatological information. It uses thinning regimes commonly applied in managed forests. FORGRO contains detailed descriptions of light interception, photosynthesis, respiration and allocation. To describe light interception in a canopy with a mixture of species, the leaf areas, weighted by the extinction coefficients, are summed over the species 
(Kropff \& Van Laar 1993). Canopy photosynthesis is calculated by integration over 5 shaded and sunlit leaf layers, assuming a uniform distribution of the leaf area over the canopy height. The photosynthesis-light response curve is modelled using a negative-exponential curve. $\mathrm{CO}_{2}$ affects both the initial light-use efficiency and the asymptote of the light response curve. The temperature dependence of the rate of photosynthesis is based on linear interpolation of experimental data, whereas an exponential function is used for the temperature dependence of the $\mathrm{CO}_{2}$ compensation point. More details of this approach can be found in Goudriaan \& Unsworth (1990), and Goudriaan \& Van Laar (1994). Respiration of living biomass depends on its biochemical composition (Penning de Vries et al. 1974), and depends on temperature according to an exponential function $\left(Q_{10}=2.1\right)$. Allocation of assimilates to the different organs is done daily and is based on empirical allocation keys, except for allocation to foliage and rescrve pools where saturation curves are used (Kramer 1995b). To focus on light interception and competition for light between species, this version of FORGRO does not take into account the effects of nitrogen and water, and thus it calculates potential growth (Goudriaan \& Van Laar 1994).

HYBRID (Friend 1993, Friend et al. in press) is an individual-tree-based model aiming to predict ecosystem structure and population dynamics based on the cycling of carbon, nitrogen and water. It incorporates establishment of seedlings, growth, mortality, litter production and feedbacks through soil processes of general plant types, on a $400 \mathrm{~m}^{2}$ plot. Light interception, photosynthesis, respiration and allocation determine growth of the individual trees. The intercepted light is distributed over the crowns of the individual trees that form the canopy, weighted by the leaf area of each individual per leaf layer and the extinction coefficient. To calculate total canopy photosynthesis, it is assumed that the photosynthetic capacity is distributed optimally with respect to radiation over the crown. Thus, the physiological properties of the foliage such as nitrogen and Rubisco content assume the same profile over the crown as the attenuation of photosynthetically active radiation (PAR). The rate of net photosynthesis of the crown is then linearly related to that of the uppermost leaf layer (Sellers et al. 1992, Friend et al. in press). The rate of net photosynthesis is calculated based on the biochemical model of Farquhar \& Von Caemmerer (1982), using a simplified version of the model PGEN (Friend et al. 1993, Friend 1995). In this model, the demand for $\mathrm{CO}_{2}$ is determined either by carboxylation limitation of Rubisco or by regeneration limitation of RuBP, which is a substrate of Rubisco. Whether the $\mathrm{CO}_{2}$ supply meets the photosynthetic demands depends on the resistance to $\mathrm{CO}_{2}$ along the pathway from outside the leaf boundary layer to the mesophyll cells. Explicit functions for the boundary layer and mesophyll resistance were used. For stomatal conductance an empirical function is used instead of the original optimization approach (Friend 1995, Friend et al. in press). For respiration an empirical approach is used, using an exponential temperature function equivalent to a $Q_{10}$ of 2.1 Allocation is done annually based on: (1) allometric relationships between diameter at breast height, tree height and total tree biomass, (2) a fixed ratio between living sapwood area and foliage area, and (3) a fixed ratio between foliage biomass and fine root biomass. Based on these constraints, an iterative procedure is used to distribute the annual net photosynthesis giving priority to: (1) foliage, (2) storage, and (3) sapwood, after a fixed amount has been allocated to the sapwood. Table 2 outlines the main features of both FORGRO and HYBRID.

The impact of frost damage on growth is described in FORGRO by complete defoliation if the daily minimum temperature is less than the state of frost hardiness. From that point onwards, the tree has to rebuild its canopy from the pool of reserves. This method is not possible in HYBRID because of the annual allocation method used. Therefore in HYBRID, the photosynthetic capacity is reduced by 50\% each time frost damage occurs. This reduction affects photosynthesis during the entire growing season (Friend et al. in press).

2.3. Scenarios and initialization. Both FORGRO and HYBRID require daily input of the following meteorological variables: minimum and maximum temperature, radiation, precipitation, vapour pressure, and wind speed. The variable evaluated was the annual net primary production, NPP ( $\mathrm{t} \mathrm{C} \mathrm{ha} \mathrm{C}^{-1} \mathrm{yr}^{-1}$ ), per species, averaged over the simulation period. To evaluate the importance of phenology with respect to climate change, the atmospheric $\mathrm{CO}_{2}$ concentration was set at $700 \mathrm{~mol} \mathrm{~mol}{ }^{-1}$, and the observed temperature series was increased uniformly by up to $7^{\circ} \mathrm{C}$ in steps of $1^{\circ} \mathrm{C}$ (denoted as $C_{700} / T_{0 \ldots, 7}$ ). The benchmark scenario $\left(C_{350} / T_{0}\right.$, ambient $\mathrm{CO}_{2}$ concentration without a change in temperature) was also examined.

For FORGRO, observations from the period 1940 to 1990 for De Bilt $\left(52^{\circ} \mathrm{N}, 6^{\circ} \mathrm{E}\right)$, located in the centre of The Netherlands, were used as input. FORGRO was initialised for a 30 yr old stand similar to that in Kramer (1995b). Initialisation of HYBRID with the same conditions was not possible because of disequilibrium of the distribution of nitrogen between the vegetation and the soil, resulting in a rapid death of many trees. Therefore, HYBRID was initialised with seedlings and the simulation period was set from 1910 to 1990 , which yields a closed canopy at age 30 . The initialization of the biomass and number of trees of a species in a mixed-species stand was one-third of that of the monospecies stand, for both FORGRO and HYBRID. 
Table 2. Outline of the features of FORGRO and HYBRID

\begin{tabular}{|c|c|c|}
\hline Process & FORGRO & HYBRID \\
\hline \multirow[t]{2}{*}{$\begin{array}{l}\text { Light interception } \\
\text { and photosynthesis }\end{array}$} & $\begin{array}{l}\text { Allows for diurnal course over sunlit } \\
\text { and shaded foliage layers }\end{array}$ & $\begin{array}{l}\text { Daily integration over crown; optimal dis- } \\
\text { tribution of foliage physiological prop- } \\
\text { erties; crown photosynthesis scales lineraly } \\
\text { with photosynthesis of uppermost leaf layer }\end{array}$ \\
\hline & Negative-exponential light response & Farquhar biochemistry (PGEN) \\
\hline Stomatal conductance & Empirical & Empirical \\
\hline Respiration & $\begin{array}{l}\text { Fixed biochemical composition; } \\
Q_{10} \text { function for temperature }\end{array}$ & $\begin{array}{l}\text { Depends on }[\mathrm{N}] \text { of organs (dynamical); } \\
\text { exponential temperature function }\end{array}$ \\
\hline Allocation & $\begin{array}{l}\text { Daily; fixed keys; saturation curves } \\
\text { for allocation to leaves and reserves }\end{array}$ & $\begin{array}{l}\text { Annual; optimization of amount of } \\
\text { foliage; sapwood and heartwood } \\
\text { area based on allometry (pipe model) }\end{array}$ \\
\hline Competition & $\begin{array}{l}\text { Stand level model; species compete for } \\
\text { light; homogeneous canopy; photosyn- } \\
\text { thesis weighted per layer for each species }\end{array}$ & $\begin{array}{l}\text { Gap model; individuals compete for } \\
\text { light; vertically explicit; horizontally } \\
\text { homogeneous }\end{array}$ \\
\hline Population dynamics & Thinning by management & $\begin{array}{l}\text { Annual establishment of all general plant } \\
\text { types; death if annual carbon gain is } \\
\text { insufficient for formation of leaf area }\end{array}$ \\
\hline Height/diameter & Empirical function & Allometric relationship \\
\hline Nutrients & (Not used) & Demand/supply hypothesis \\
\hline Water & (Not used) & Single layer bucket \\
\hline Soil & (Not used) & Century model; 1 layer; 4 litter pools \\
\hline Frost damage & Complete defoliation & $\begin{array}{l}\text { Reduction of photosynthetic capacity } \\
\text { during growing season }\end{array}$ \\
\hline
\end{tabular}

\section{RESULTS}

\subsection{Phenology and spring frost damage}

The differences in the mean date of leaf unfolding and in the response to an increase in temperature between the phenological types (Table 1) affect the duration of the growing season. This results in differences in available radiation during the growing season with increasing temperature (Fig. 1). Both the regression and the dynamic approach show that during the growing season of Quercus, less radiation is available than during the growing season of both Fagus and Betula. Furthermore, for Fagus the available radiation exceeds that of Betula if the temperature increases by more than about $3^{\circ} \mathrm{C}$. However, the increase of the available radiation with temperature is larger according to the dynamic approach than based on the regression approach, because the former predicts a greater advancement of leaf unfolding with temperature than the latter (Table 1).

The differences between the phenological types in the mean date of leaf unfolding and in the response to an increase in temperature (Table 1) result further-

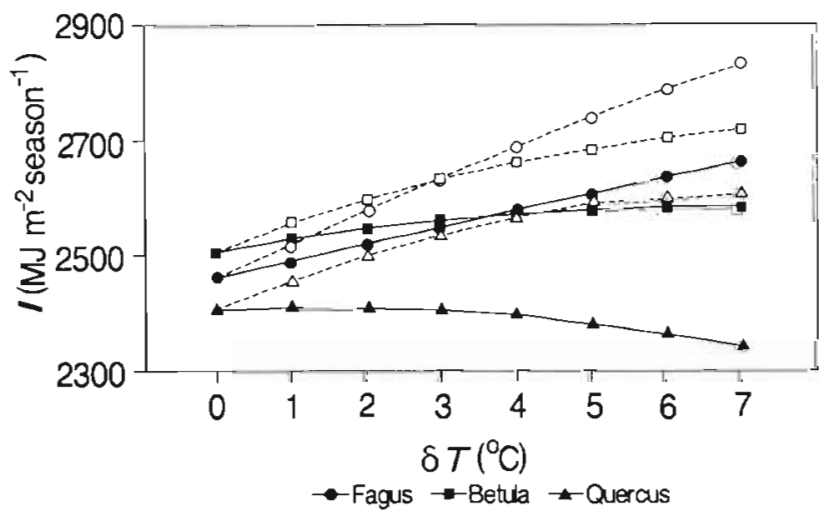

Fig. 1. Global radiation available during the growing season (I). Means for 1940 to 1990 in The Netherlands. Solid lines and closed symbols: regression approach; dashed lines and open symbols: dynamic approach. $\delta T$ : temperature scenario imposed on the observed values for the period 1940 to 1990 in The Netherlands

more in differences in the occurrence of frost around the date of leaf unfolding (Fig. 2). The earlier a species unfolds its leaves, the higher the probability of its 


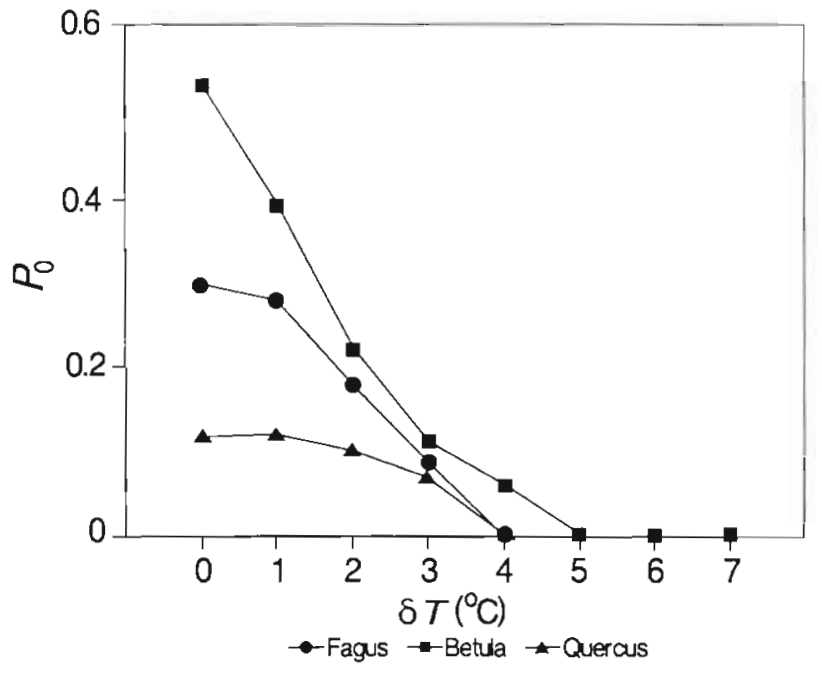

Fig. 2. Probability of sub-zero temperature in a symmetrical $11 \mathrm{~d}$ interval around the date of leaf unfolding $\left(\mu_{0}\right)$ according to the dynamic approach. $\delta T$ : temperature scenario imposed on the observed values

being damaged by spring frost. Thus for the phenological types considered, Betula has the highest probability of frost damage and Quercus the lowest, whereas Fagus takes an intermediate position. With increasing temperature this probability quickly decreases for these phenological types (Fig. 2).

\subsection{Growth}

Both available radiation and frost damage influence photosynthesis and consequently growth. In the following, the results of both the regression and the dynamic approach for phenology and frost hardiness are presented, using the models FORGRO and HYBRID.

\subsubsection{FORGRO}

Based on the regression approach, without the impacts of frost damage, the pattern of NPP for a monoculture stand is similar to that of the amount of radiation available during the growing season (Figs. 1 \& 3). Thus, NPP of Fagus exceeds that of Betula if the increase in temperature is larger than about $2^{\circ} \mathrm{C}$, whereas these values for Quercus are consistently lower than for both Fagus and Betula.

The effect of frost damage on the results of the $C_{700} / T_{0}$ scenario, using the fixed frost damage threshold, is a reduction of the NPP of Betula in the monospecies stands by $4 \%$, but virtually no change of the NPP of Fagus and Quercus (Fig. 3). In mixed-species stands, however, the same level of frost damage results in much larger differences between the phenological types (Fig, 3). The reduction of the NPP of Betula, compared with the non-damaged situation, leads to an increase of the NPP of Fagus and Quercus. Frost damage affects the NPP if the temperature increase is less than $3^{\circ} \mathrm{C}$, although the probability of sub-zero temperature then is still approximately $10 \%$ for each of the phenological types (Fig. 2).

Both the regression and the dynamic approach yield similar responses of NPP with increasing temperature (Figs. $3 \& 4$ ). The differences between the approaches are: (1) the NPP of the phenological types diverges more in the case of the dynamic approach, because of the greater divergence of the amount of available radiation during the growing season (Fig. 1), and (2) the impact of frost damage on NPP of the mixedspecies stands is less in the case of the dynamic approach for frost hardiness.

The reason that the dynamic approach for frost hardiness affects NPP less than the constant hardiness threshold is depicted in Fig. 5: the fre-
Fig. 3. Net primary production of a mono- and mixed-species stand according to FORGRO, using the regression approach for phenology and frost hardiness. Solid lines: no effect of frost damage; dashed lines: effect of frost damage; open symbols: results of benchmark scenario without frost damage. $\delta T$ : temperature scenario imposed on the observed values 


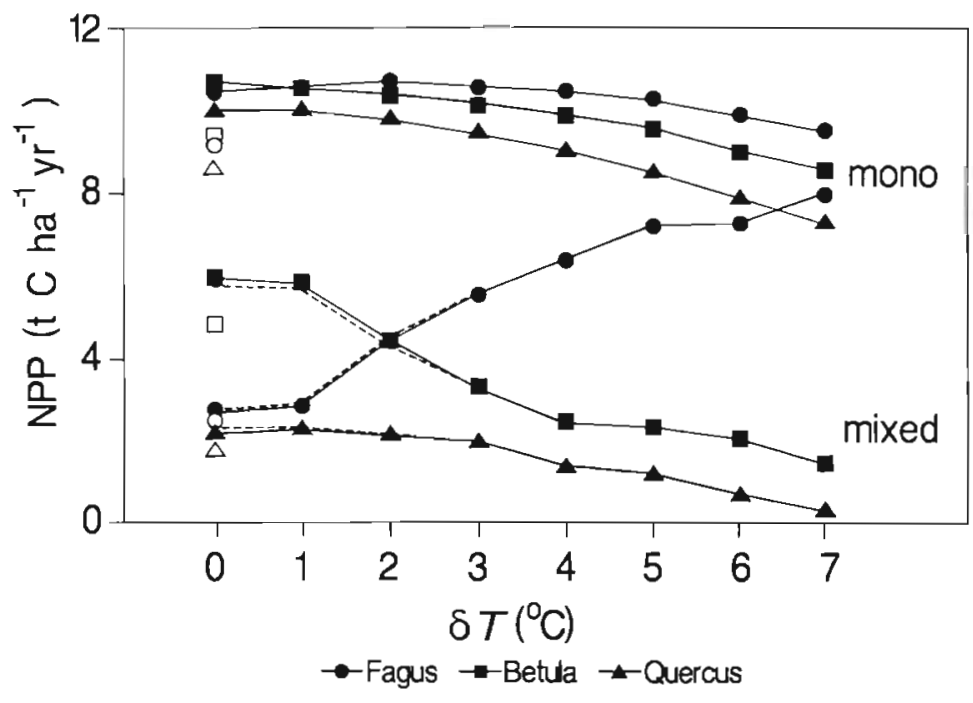

Fig. 4. Net primary production of a mono- and mixed-species stand according to FORGRO, using the dynamic approach for phenology and frost hardiness. Solid lines: no effect of frost damage; dashed lines: effect of frost damage; open symbols: results of benchmark scenario without frost damage. $\delta T$ : temperature scenario imposed on the observed values

quency of frost damage is larger based on the regression approach (constant threshold) than according to the dynamic approach. Based on the parameterization of Leinonen et al. (1995) for the frost hardiness model, the minimum level of frost hardiness is attained after the moment of leaf unfolding. Furthermore, the period between the date of leaf unfolding and the date that the minimum level of frost hardiness is attained increases with rising temperature, thus reducing the frequency of frost damage.

\subsubsection{HYBRID}

If population dynamics are also taken into account to assess the importance of phenology with respect to intercepted radiation and frost damage, then a complex picture emerges (Fig. 6). The progression of the leaf area index (LAI) in a monospecies stand of Betula differs considerably between the scenarios, because of the mortality of trees and the establishment of new seedlings. For example, the $C_{700} / T_{0}$ scenario results in 1 large tree in the gap (of $400 \mathrm{~m}^{2}$ ) after about $30 \mathrm{yr}$. When this tree dies, the build-up of the stand starts again. The same pattern is found if the temperature rises by $1^{\circ} \mathrm{C}$ (not shown), but not within the selected simulation period if the temperature rises more. Frost damage, using the dynamic approach, affects the dynamics of Betula if the temperature increase is less than $3^{\circ} \mathrm{C}$, but it especially reduces the formation of leaf area on seedlings in the $C_{350} / T_{0}$ and $C_{700} / T_{0}$ scenarios. Characteristically, the annual NPP is highest during the build-up phase. The average NPP depends therefore, on the period over which this average is calculated, because in some cases the simulation period covers 2 cycles of forest succession, and in other cases less than 1 cycle (Fig. 6). This makes it difficult to choose the best period over which NPP should be averaged.

When NPP is averaged over the entire 80 yr simulation period, Quercus yields the lowest NPP, Fagus the highest NPP when the temperature rise exceeds $1^{\circ} \mathrm{C}$, and Betula is affected most by frost damage (Figs. $7 \& 8$ ). When the dynamic approach for frost hardiness is combined with HYBRID, then the effect of frost hardiness on NPP is reduced (results not shown), similar to the results found for FORGRO.

For a more detailed analysis, however, the pattern of forest dynamics must also be considered. Then it can be seen why including frost damage in some cases

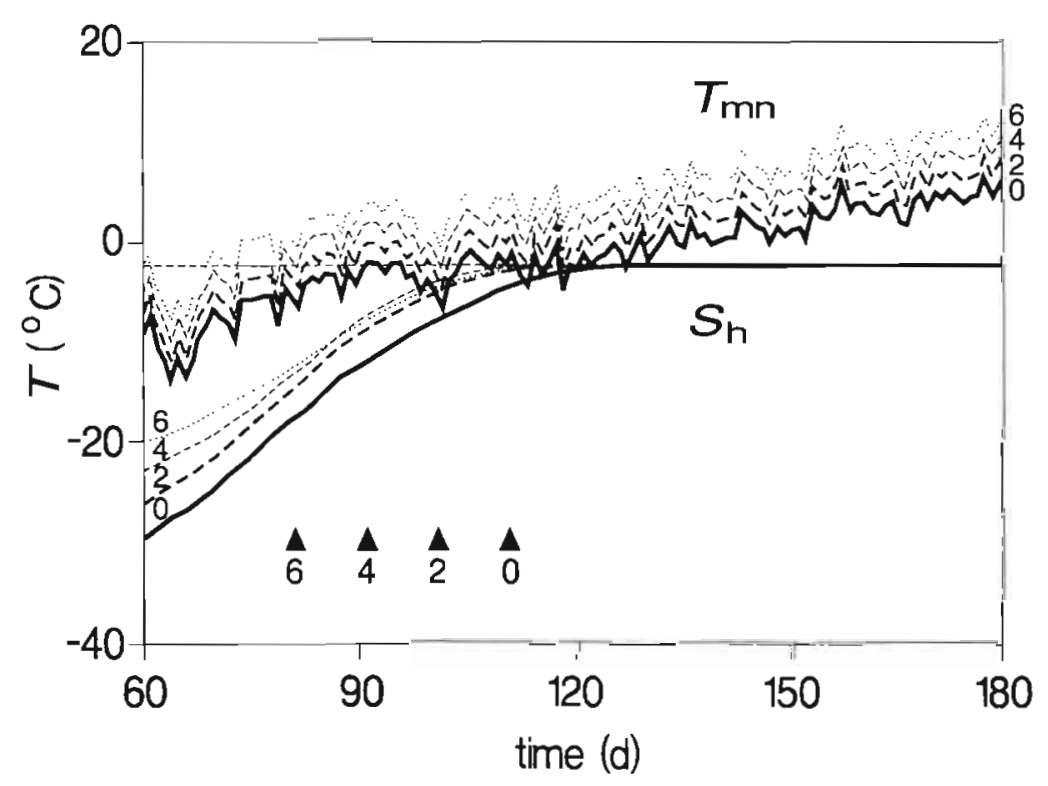

Fig. 5. Effect of a rise in temperature by 2,4 , and $6^{\circ} \mathrm{C}$ on frost damage of Betula. Frost damage occurs when the minimum daily temperature is less than the level of frost hardiness. $T_{\mathrm{mn}}$ : lowest daily minimum temperature in the period 1940 to 1990; $S_{\mathrm{h}}$ : mean of the actual state of frost hardiness during the same period; horizontal dashed line at $-2.3^{\circ} \mathrm{C}$ : regression approach for frost hardiness; triangles: mean date of leaf unfolding, according to the dynamic approach for phenology 


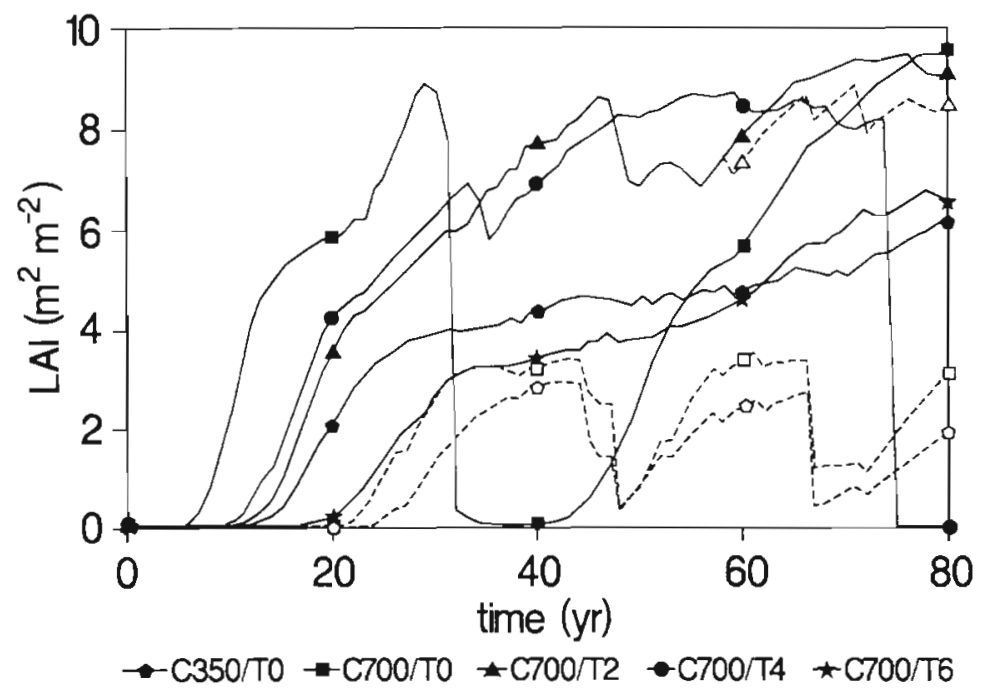

Fig. 6. Progression of the leaf area index (LAI) of a monospecies stand of Betula according to HYBRID, using the dynamic approach for phenology. Solid lines and closed symbols: no effects of frost damage; dashed lines and open symbols: effect of frost damage using the regression approach for frost hardiness (constant frost hardiness threshold at $-2.3^{\circ} \mathrm{C}$ )

causes an increase of the NPP of a phenological type: this can be either because of competition, or because of the selected simulation period. An example of the first mechanism is shown in Fig. 9. Betula is affected most by frost damage. Thus, a reduction of the NPP of Betula results in an increase of the NPP of both Fagus and Quercus. An example of the second mechanism is

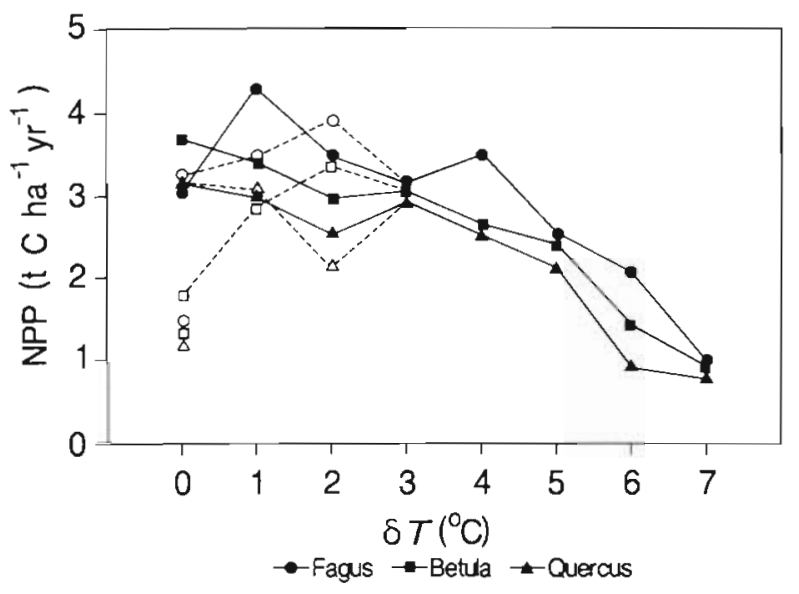

Fig. 7. Net primary production of a monospecies stand according to HYBRID, using the dynamic approach for phenology. Solid lines and closed symbols: no effect of frost damage; dashed lines and open symbols: effect of frost damage, using the regression approach for frost hardiness; single open symbols: results of benchmark scenario without frost damage. $\delta T$. temperature scenario imposed on the observed values shown in Fig. 10. The advancement of the death of a tree due to frost damage causes a reduction in biomass and thus in the costs for respiration which exceeds the loss in photosynthesis because of a reduction in LAI. Since the LAI is still rather high for a deciduous species (Fig. 10), the NPP of the last 15 yr simulated including frost damage exceeds the NPP without the effects of frost damage (Fig. 8).

\section{DISCUSSION AND CONCLUSIONS}

With respect to the effects of differences between species in both phenological response and spring frost damage on growth in mixed-species deciduous forests, in relation to an increased temperature and atmospheric $\mathrm{CO}_{2}$ concentration, both FORGRO and HYBRID show: (1) that the differences in NPP of the 3 phenological types considered are enhanced when grown in mixedspecies stands compared to monospecies stands. These differences increase with rising temperature, because the differences in the duration of the growing season between the phenological types increase with temperature. And (2) that the consequences of frost damage for growth are more prominent in mixed-species stands than in monospecies stands because, in the latter, a reduction in leaf area

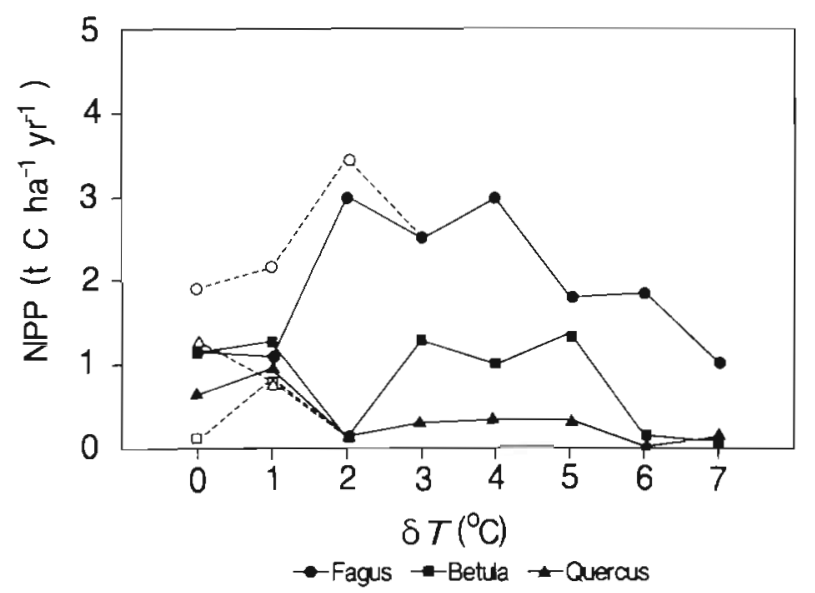

Fig. 8. Net primary production of a mixed-species stand according to HYBRID, using the dynamic approach for phenology. Solid lines and closed symbols: no effect of frost damage; dashed lines and open symbols: effect of frost damage, using the regression approach for frost hardiness. $\delta T$ : temperature scenario imposed on the observed values 


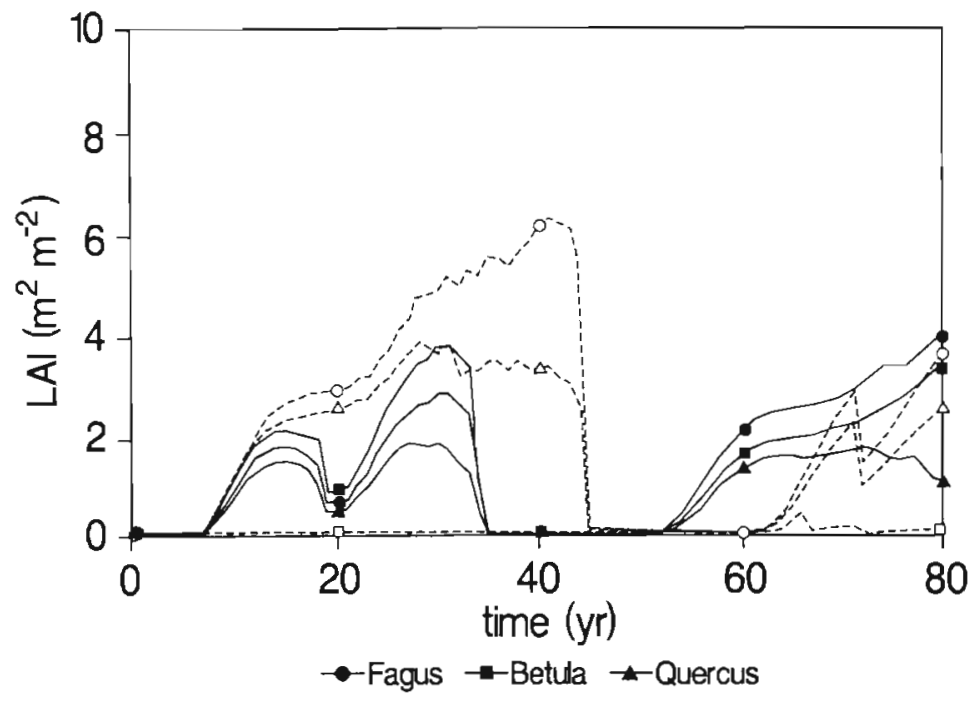

Fig. 9. Progression of the leaf area index (LAI) of a mixed-species stand based on the $C_{700} / T_{0}$ scenario according to HYBRID, using the dynamic approach for phenology and frost hardiness. Solid lines and closed symbols: no effect of frost damage; dashed lines and open symbols: effect of frost damage. $\delta T$ : temperature scenario imposed on the observed values of plots for detecting a response of forest growth to a changing environment, when individual trees die and new trees emerge during the observation period. The results of HYBRID show that the results may be unexpected but can be explained by more detailed analysis.

Regarding the accuracy of the dynamic approach compared to the regression approach for the timing of leaf unfolding, both approaches show similar values and responses of NPP to the scenarios, for the monospecies and the mixed-species stand according to FORGRO (Figs. $3 \& 4$ ). Although more light is available during the growing season according to the dynamic approach, photosynthesis still cannot compensate for the increase in respiration, if the temperature increases by more than $3^{\circ} \mathrm{C}$. The differences in NPP between the phenological types are, however, enhanced according to the dynamic approach because the differences in the increase of the duration of the growing season, compared to the regression approach.

Regarding the accuracy of the dynamic approach compared to the regression approach for frost hardiness, the regression approach shows a greater frequency of frost damage, because according to the dynamic approach the minimum level of frost hardi- due to frost damage is quickly obviated by a rebuilding of the canopy, whereas in a mixed-species stand the rebuilding of the canopy is hampered by the presence of foliage of the trees which were less affected by the frost damage. The NPP is higher according to FORGRO, because of the dynamics of the num. ber of trees simulated by HYBRID. NPP is low during the seedling phase, with a low leaf area index, and when there is 1 mature tree only, and NPP is highest during the build-up phase.

In FORGRO, the NPP is more constant throughout the simulation period than in HYRBID. The sensitivity of the NPP to the simulation period in HYBRID can be circumvented by averaging over several plots that are in a different stage of succession, and using a longer simulation period. In that case smooth lines are found, similar to those resulting from FORGRO. This was not done here because the focus was on the importance of phenology and spring frost damage for natural stands with individual trees of different age and size (HYBRID) compared to its importance for managed stands with even-aged and even-sized individuals for each species (FORGRO). Experiments in natural mixed forests face the same difficulty of selecting the proper averaging period and number

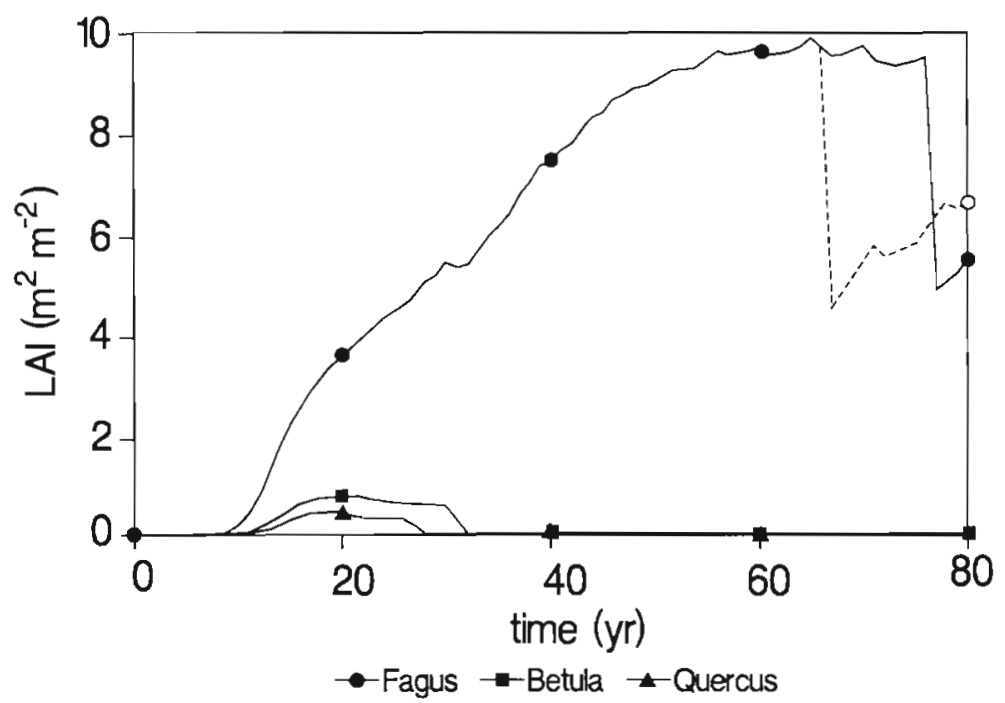

Fig. 10. Progression of the leaf area index (LAI) of a mixed-species stand based on the $C_{700} / T_{2}$ scenario according to HYBRID, using the dynamic approach for phenology and frost hardiness. Solid lines and closed symbols: no effect of frost damage; dashed line and open symbols: effect of frost damage. $\delta T$ : temperature scenario imposed on the observed values 
ness is attained after the date of leaf unfolding, thus reducing this frequency (Fig. 5). According to FORGRO, NPP is reduced more in the case of the regression approach, especially in mixed-species stands (Figs. 3 \& 4). However, neither approach qualitatively affects the outcome of competition. The impact of frost damage on growth is less according to FORGRO than according to HYBRID. In FORGRO the canopy is quickly rebuilt, if there are sufficient reserves. In HYBRID, the seedling stage is especially affected by frost damage, which delays the moment when the build-up phase starts (Fig, 6). This delay consequently reduces the mean NPP of the simulation period (Fig. 7). Thus, it is important to assess the degree of injury brought about by frost to evaluate climate change impacts on the transient dynamics of temperate-zone deciduous forests. This is, however, not constant but depends on the freezing rate, phenological stage, tissue hydration, soluie in sap, and external wetness (Santibanez 1994). Furthermore, the dehardening of Pinus sylvestris not only depends on temperature, but was found to be hastened with elevated $\mathrm{CO}_{2}$ (Repo et al. 1996).

Validation of the models FORGRO and HYBRID has not been attempted in this study, although the models have been successfully applied to specific situations (Mohren 1994, Friend et al. 1993). De Wit (1970) has already stated that 'fitting a mechanistic model to data is a disastrous way of working... [S]ince there are many parameters and many equations involved this is not difficult... [T] $T$ he technique reduces into the most cumbersome and subjective technique of curve fitting that can be imagined'. However, processes can be calibrated and tested against data, and subsequently the importance of a process for forest growth can be evaluated by models on forest growth. This approach was taken for the importance of phenology and spring frost damage for the evaluation of climate change effects on mono- and mixed-species forests by comparison of managed homogeneous stands to natural heterogenous stands. The results indicate that relatively small differences in the duration of phenological stages, in combination with spring frost damage, have profound impacts on the outcome of competition between deciduous tree species.

Acknowledgements. This study has benefited from the comments by Prof J. Goudriaan, Dr G. M. J. Mohren, and the PhD students of the C. T de Wit Graduate School of Production Ecology. This research was supported by the EC Environment Research Programme (contract: EV5V-CT94-0468, Climatology and Natural Hazards). The funding of a one-month visit to Dr A. D. Friend by the EU-COST programme, action 614: Impact of Elevated $\mathrm{CO}_{2}$ Levels, Climate Change and Air Pollutants on Tree Physiology (ICAT) is gratefully acknowledged.

\section{LITERATURE CITED}

De Wit CT (1970) Dynamic concepts in biology. In: Setlik I (ed) Prediction and measurements of photosynthetic productivity. Pudoc, Wageningen, p 19-25

Farquhar GD, Von Caemmerer S (1982) Modelling of photosynthetic response to environmental conditions. In: Lange OL, Nobel PS, Osmond CB, Ziegler H (eds) Physiological plant ecology II: Water relations and carbon assimilation, 12B. Springer-Verlag, Berlin, p 549-587

Friend AD (1993) Use of a model of photosynthesis and leaf microenvironment to predict optimal stomatal conductance and leaf nitrogen partitioning. Plant Cell Environ 14 895-905

Friend AD (1995) PGEN: an integrated model of leaf photosynthesis, transpiration, and conductance. Ecol Model 77 : $233-255$

Friend AD, Shugart HH, Running SW (1993) A physiologybased gap model of forest dynamics. Ecology 74:792-797

Friend AD, Stevens AK, Knox RG, Cannell MGR (in press) A process-based, terrestrial biosphere model of ecosystem dynamics (Hybrid v 3.0). Ecol Model

Goudriaan J, Unsworth MII (1990) Implications of increasing carbon dioxide and climate change for agricultural productivity and water resources. In: Impact of carbon dioxide, trace gases, and climate change on global agriculture. ASA Spec Publ 53:111-130

Goudriaan J, Van Laar HH (1994) Modelling potential crop growth processes. Kluwer Academic Publishers, Dordrecht

Hänninen $\mathrm{H}$ (1990) Modelling bud dormancy release in trees from cool and temperate regions. Acta For Fenn 213:1-47

Kramer K (1994) A modelling analysis on the effects of climatic warming on the probability of spring frost damage to tree species in The Netherlands and Germany. Plant Cell Environ 17:367-377

Kramer K (1995a) Phenotypic plasticity of the phenology of seven European tree species, in relation to climatic warming. Plant Cell Environ 18:93-104

Kramer K (1995b) Modelling comparison to evaluate the importance of phenology for the effects of climate change in growth of temperate-zone deciduous trees. Clim Res 5: $119-130$

Kropff MJ, Van Laar HH (eds) (1993) Modelling crop-weed interactions. CAB Interrational, Wallingford

Leinonen I, Repo T, Hänninen H, Burr KE (1995) A secondorder dynamic model for the frost hardiness of trees. Ann Bot 76:89-95

Lieth $H$ (ed) (1974) Phenology and seasonality modeling. Ecological studies. Analysis and synthesis, Vol 8. SpringerVerlag, Berlin

Mohren GMJ (1987) Simulation of forest growth, applied to Douglas fir stands in the Netherlands. Thesis, Wageningen Agricultural University

Mohren GMJ (1994) Modelling Norway spruce growth in relation to site conditions and atmospheric $\mathrm{CO}_{2}$. In: Veroustraete F, Ceulemans R (eds) Vegetation, modelling and climate change effects. SPB Academic Publishing, The Hague, p $7-22$

Penning de Vries FWT, Brunsting A, Van Laar HH (1974) Products, requirements and efficiency of biosynthesis; a quantitative approach. J Theor Biol 45:339-377

Repo T, Hänninen H, Kellomäki S (1996) The effects of longterm elevation of air temperature and $\mathrm{CO}_{2}$ on the frost hardiness of Scots pine. Plant Cell Environ 19:209-216

Santibanez F (1994) Crop requirements - temperate crops. In: Griffiths JF (ed) Handbook of agricultural meteorology. Oxford University Press, Oxford, p 174-188 
Sarvas R (1974) Investigations on the annual cycle of development of forest trees. II. Autumn dormancy and winter dormancy. Comm Inst For Fenn 84

Sellers PJ, Berry JA, Collatz GJ, Field CB, Hall FG (1992)

Editor: G. Esser, Gießen, Germany
Canopy reflectance, photosynthesis, and transpiration. III. A reanalysis using improved leaf models and a new canopy integration scheme. Remote Sens Environ 42 : $187-216$

Manuscript first received: October 18, 1995

Revised version accepted: April 3, 1996 